Josefina Marc

Lic. en Trabajo Social (UNR)

E-mail: josefina_marc@hotmail.com

Natalia Lascialandare

Estudiante de la Lic. en Trabajo Social (UNR)

E-mail: natalialacialandare_377@hotmail.com

Pilar Osella

Estudiante de la Lic. en Trabajo Social (UNR)

E-mail: osellapilar@hotmail.com

\title{
Ana Josefina Arias \\ Pobreza y modelos de intervención: aportes para la superación del modelo de asistencia y promoción
}

$1^{\circ}$ edición, Ciudad Autónoma de Buenos Aires: Espacio Editorial, 2012 220 páginas | ISBN 978-950-802-345-2.

La autora del libro es Trabajadora Social, Magíster en Políticas Sociales y Doctora en Ciencias Sociales (UBA). Ha ejercido como trabajadora social en distintas dependencias estatales y en organizaciones sociales y políticas. Se ha especializado como investigadora en Intervención Social y Pobreza. Actualmente se desempeña como directora de la carrera de Trabajo Social de la Facultad de Ciencias Sociales de la UBA.

El objetivo general del libro es realizar un análisis de los modelos de intervención sobre la pobreza en Argentina a partir de la década del '60 hasta la actualidad. Arias responde a este objetivo desde una perspectiva teórica novedosa en los análisis del Trabajo Social y su historia, proponiendo una periodización y modelos en torno a las intervenciones sobre la pobreza, utilizando como dimensiones ordenadoras de esos modelos: características socio-políticas del período, aportes desde las Ciencias Sociales, rol del Estado, idea de sujeto, definición de lo comunitario, definición de lo promocional, definición de lo asistencial, profesionalización de la intervención. Dimensiones necesarias para pensar continuidades y rupturas en los diferentes modelos de intervención.

El libro tiene como insumos su tesis de maestría, material recabado en investigaciones, entrevistas y registro de actividades con organizaciones sociales. 
Brinda herramientas que invitan a la reflexión, investigación e intervención en políticas sociales.

El libro consta de un prólogo escrito por el Dr. Alfredo Carballeda, una introducción y siete capítulos, siendo el último presentado a modo de conclusión.

El capítulo I es elaborado a partir de autores como Simmel, Paugam, Donzelot y Dubet para pensar las formas sociales, las instituciones, lo social, la pobreza, el vínculo asistencial y la intervención social.

La autora sitúa la pobreza en el marco de lo social apoyándose en el planteamiento de Jaques Donzelot, quien entiende lo social como una invención con la finalidad de sostener la integración social en el capitalismo de las sociedades democráticas. Siguiendo esta línea, Arias introduce el tema de la intervención en lo social, su origen, institucionalización y función. Entiende al Trabajo Social como la disciplina por excelencia configurada para desempeñar procesos de socialización.

Por último, para situar la lectura de los capítulos siguientes, anticipa algunas definiciones preliminares sobre la idea de asistencia y promoción social en tanto actividades que desde los años '60 organizaron la intervención en el campo del Trabajo Social. Para definir asistencia recurre a Castel, Ander-Egg, Alayón, en tanto que para la definición de promoción social se vale de Dieguez.

En el capítulo II comienza recuperando estudios sobre la pobreza en Argentina, como el informe Bialet-Massé de 1904 como primer antecedente en la discusión sobre la pobreza. Retoma la presencia del higienismo dentro de las corrientes positivistas y la construcción del sujeto a partir de explicaciones raciales, ya que este tipo de lectura volverá a utilizarse en el desarrollismo. La autora señala que entre estos dos momentos se produjeron transformaciones a nivel internacional y nacional, destacando la aparición del Peronismo y de un Estado "protector", versión autóctona y adaptada del estado de bienestar. Distingue fundamentalmente las políticas de atención hacia los pobres identificadas con las políticas asistenciales de las políticas sociales universales. Presenta brevemente los cambios en el período justicialista, entre ellos en relación a la concepción de la pobreza.

En el capítulo III, expone los cambios ocurridos durante la etapa desarrollista, centrándose en las nuevas estructuras del Estado y en la determinación de los organismos internacionales en el curso de las políticas sociales en Latinoamérica. Reconoce aquí la instauración de una forma específica de tratamiento de la pobreza que incorpora al componente asistencial la "promoción social", produciendo una ruptura con la etapa anterior. Posteriormente, analiza el desarrollo de las ciencias sociales, los teóricos de la modernización y la influencia de Talcott Parsons. Argumenta así la relación entre los fundamentos teóricos y la introducción de la promoción social en el modelo de intervención, destacando la baja escala de la asistencia. 
Analiza la promoción popular y el desarrollo de la comunidad como intervenciones similares. Denota la centralidad que adquiere la comunidad como blanco de intervención social y a los/as trabajadores/as sociales como "agentes de cambio”. Cierra el capítulo describiendo cómo se instituye este modelo.

En el capítulo IV realiza una contextualización de la etapa entre los años '60 y '70 reseñando ciertas perspectivas críticas y conflictos sociales. Expone los principales debates teóricos, entre ellos, la teoría de la dependencia de Cardoso y Faletto y los aportes de José Nun. Recorre brevemente el pensamiento social que pone en el centro de la escena "lo nacional", resaltando las contribuciones de Jauretche y Scalabrini Ortiz.

Destaca los cambios al interior de la Iglesia Católica a partir del Concilio Vaticano II, con los cuestionamientos liberacionistas y la opción por los pobres. Trabaja la incidencia del pensamiento de Paulo Freire en este proceso y las contribuciones que realiza este autor para pensar la intervención social.

Aborda también la radicalización de los sectores medios en la época, lo que al interior del Trabajo social genera consecuencias en las lecturas teórico-metodológicas del modelo de intervención de asistencia y promoción. Da cuenta de los aportes militantes a la disciplina y ubica el proceso de reconceptualización, exhibiendo sus contribuciones y limitaciones. Resalta cómo incidió la valorización de lo popular como espacio de resistencia política en la discusión de la profesionalización de la intervención social.

En el capítulo V, luego de describir brevemente los cambios que instaló la dictadura cívico militar 1976-1983, la autora aborda los nuevos enfoques entorno a las concepciones de marginalidad de la pobreza y de ciudadanía. Presenta los aportes de Robert Castel, fundamentalmente en relación a los conceptos de vulnerabilidad y desafiliación social.

Dedica un apartado especial a la reestructuración del Estado y las políticas sociales en relación a los condicionamientos de los organismos internacionales. Analiza esta relación mediante la descripción de dos experiencias de intervención: el Programa Alimentario Nacional y el Programa Alimentario Probienestar.

Precisa cómo estos cambios modifican las intervenciones profesionales, planteando la desprofesionalización de las prácticas asistenciales y una tecnificación de lo promocional. Cierra el capítulo identificando las modificaciones del modelo de asistencia y promoción en la etapa neoliberal.

En el capítulo VI identifica las transformaciones del vínculo asistencial en la primera década del siglo XXI, para ello se vale principalmente de entrevistas y grupos focales. Como en los capítulos anteriores, da cuenta de los aportes de las ciencias sociales abonando a la discusión sobre las propuestas de asignaciones monetarias, economía social y nuevas lecturas sobre la pobreza estructural. Analiza el Programa Jefes y Jefas de Hogar Desocupados, el Programa Familias 
y la Asignación Universal por Hija/o como experiencias de intervención que visibilizan las principales transformaciones en las políticas paradigmáticas.

En el capítulo VII titulado "Conclusiones" retoma brevemente el recorrido realizado a lo largo del trabajo, haciendo una lectura de rupturas y continuidades del modelo de intervención. Se posiciona respecto al componente promocional y al asistencial reconociendo en la actualidad indicios de ruptura, retomando la idea de programa institucional planteado por Dubet para caracterizar y/o detallar cómo éste entra en crisis. Resignifica el concepto de asistencia desde una lógica de derechos.

Una de las riquezas de este libro se encuentra en la temática que aborda, ya que es nodal en el Trabajo Social. El recorrido que la autora realiza respecto a la des-reconstrucción de ciertas categorías -como pobreza, asistencia y promoción- es sumamente interesante ya que, a nuestro entender, las mismas se encuentran desjerarquizadas en la formación del Trabajo Social.

Destacamos en primera instancia la recuperación de las prácticas profesionales y de investigación que la autora realiza. En esta línea, nos resulta interesante la recuperación de la historia oral de los/as entrevistados/as. El lenguaje y la escritura del libro permiten un acceso a fuentes y procesos sin vulgarizar, sin regodeos en lenguajes encriptados y con precisiones conceptuales. Pone en diálogo la práctica y la reflexión teórica, permitiéndonos pensar la producción de conocimiento superando la falsa escisión teoría-práctica.

En segundo lugar, resaltamos el anclaje en la órbita nacional y latinoamericana. La autora resignifica los aportes de autores característicos de la formación en Trabajo Social situando la intervención en la singularidad de este contexto. A su vez, enriquece el análisis, conjugando las categorías marxistas con pensadores del revisionismo histórico de incidencia en el ideario peronista, así como con los aportes del cristianismo de la liberación que permiten repensar, no sólo el contexto, sino también la fundamentación de las intervenciones enmarcadas en un proyecto societal.

El libro instala interrogantes que permiten repensar la intervención profesional en aspectos y concepciones que en el Trabajo Social se encuentran naturalizados. La autora trae discusiones actuales que resultan de suma implicancia no sólo para los profesionales de esta disciplina, sino también para el conjunto de quienes intervienen en lo social. 